\title{
A taxonomic review of the genus Asterostegus (Echinodermata: Ophiuroidea), with the description of a new species
}

\author{
Masanori OKANISHI ${ }^{1,3,{ }^{*}} \&$ Toshihiko FUJITA ${ }^{2,4}$ \\ ${ }^{1}$ Seto Marine Biological Laboratory, Field Science Education and Research Center, Kyoto University, \\ 459 Shirahama, Nishimuro, Wakayama, 649-2211 Japan \\ ${ }^{2}$ National Museum of Nature and Science, 4-1-1 Amakubo, Tsukuba, Ibaraki, 305-0005 Japan \\ *Corresponding author. E-mail: mokanishi@tezuru-mozuru.com \\ ${ }^{3}$ urn:1sid:zoobank.org:author:6F730D3A-A6FC-41FD-B5F6-9629D55E4547 \\ ${ }^{4}$ urn:Isid:zoobank.org:author:D5B6C696-9E5B-4012-A9A9-4716DD2BA2C3
}

\begin{abstract}
A revision of the genus Asterostegus Mortensen, 1933 (Echinodermata: Ophiuroidea: Euryalidae) is based on seven specimens, including the holotype of Asterostegus maini McKnight, 2003. A new species, Asterostegus sabineae sp. nov., is described from off Reunion Island and two other species, A. tuberculatus Mortensen, 1933 and A. maini, are redescribed. A tabular key to the three species of the genus Asterostegus is provided. Some terminology of the taxonomy of euryalid ophiuroids is revised.
\end{abstract}

Keywords. Taxonomy, brittle stars, Asterostegus sabineae, new species, Indo-Western Pacific.

Okanishi M. \& Fujita T. 2014. A taxonomic review of the genus Asterostegus (Echinodermata: Ophiuroidea), with the description of a new species. European Journal of Taxonomy 76: 1-18. http://dx.doi.org/10.5852/ejt.2014.76

\section{Introduction}

The family Euryalidae Gray, 1840 is widely distributed in the Indo-West Pacific (Kroh 2004). The genus Asterostegus (Ophiuroidea: Euryalida: Euryalidae) was erected by Mortensen (1933b) monotypically for Asterostegus tuberculatus Mortensen, 1933 and is currently composed of A.tuberculatus Mortensen, 1933 and A. maini McKnight, 2003. The genus is morphologically related to the genus Astroceras (Euryalidae), but is clearly distinguished by having oral interradial plates (Mortensen 1933b; McKnight 2003).

The monophyly of this genus is confirmed by a recent molecular phylogenetic study (Okanishi \& Fujita 2013), but taxonomic works on Asterostegus species are scarce. Asterostegus tuberculatus was originally described by Mortensen (1933b) based only on the holotype, but a second specimen was recorded by Clark \& Courtman-Stock (1976). Asterostegus maini was also originally described by McKnight (2003), based only on the holotype. McKnight (2003) distinguished the aforementioned two species chiefly by the arrangement and size of tubercles on the radial shields and lateral bars, and by the arrangement of plates on the oral interradius. However, these descriptions lacked quantitative accounts of sizes of the tubercles (Mortensen 1933b; Clark \& Courtman-Stock 1976; McKnight 2003), making it difficult 
to distinguish the two species of Asterostegus as well as to compare newly collected specimens of Asterostegus.

In the present study, Asterostegus maini and A. tuberculatus are redescribed based on the holotype of A. maini and one newly collected specimen of A. tuberculatus. A new species of Asterostegus is based on five specimens collected from off Madagascar. In recent descriptions of ophiuroids, photographs and/or drawings of each part of the body, as well as SEM images of each ossicle, provide valuable taxonomic information (e.g., Okanishi \& Fujita 2009; Okanishi \& Fujita 2011a, 2011b; Okanishi \& Fujita 2014; Martynov 2010). To date, drawings and photographs of A. tuberculatus and A. maini have been presented of limited parts of the body (Mortensen 1933b; McKnight 2003) only. Herein we present detailed photographs of many parts of the body and SEM images of separated ossicles.

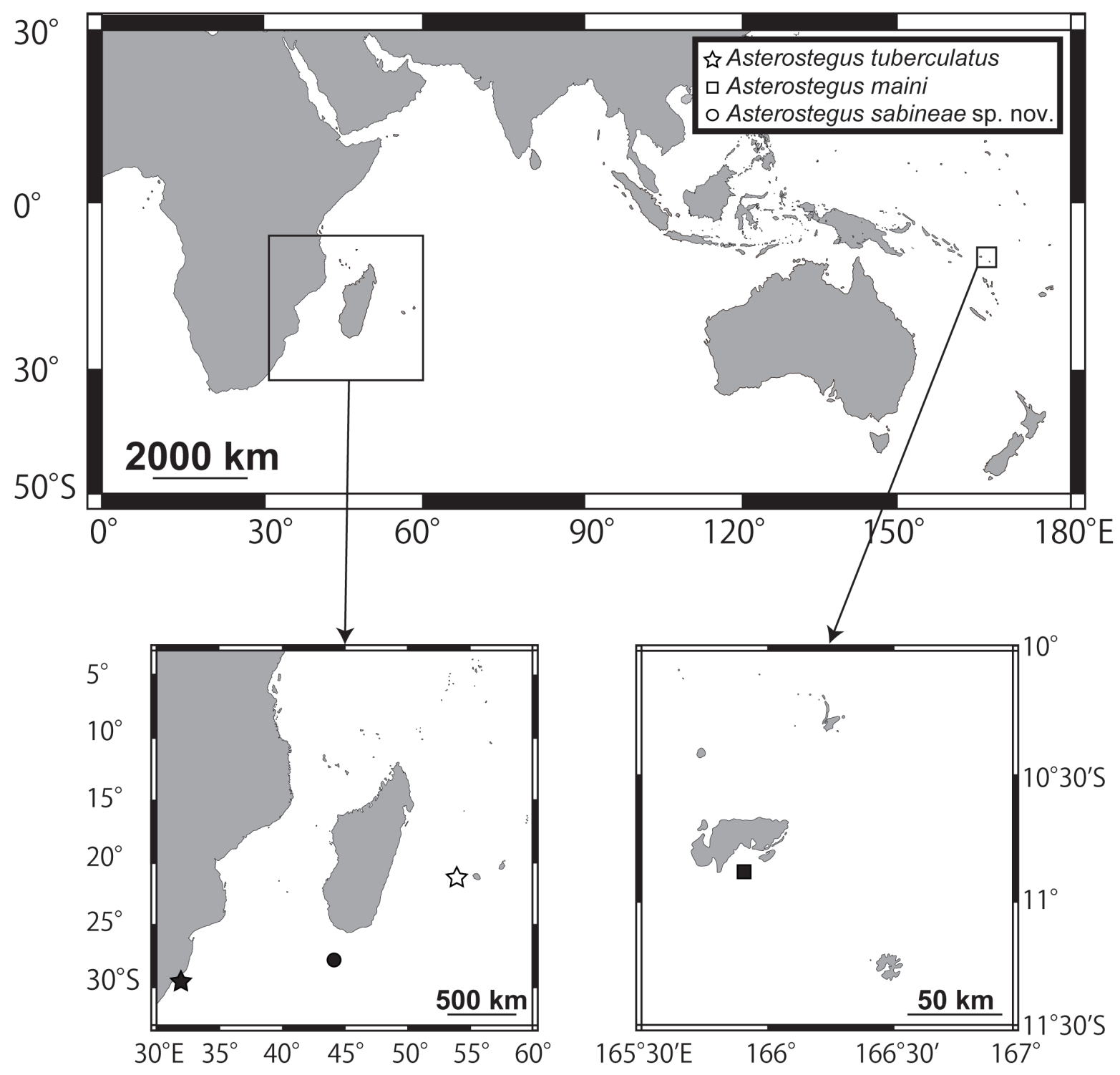

Fig. 1. Known distribution of Asterostegus maini McKnight, 2003, A. sabineae sp. nov., and A. tuberculatus Mortensen, 1933 are indicated by square, circle and star shaped symbols respectively. Solid symbols indicate the type locality of each species. 


\section{Material and methods}

The seven specimens used in this study are deposited in the National Institute of Water and Atmospheric Research (NIWA), Muséum National d'Histoire Naturelle (MNHN) and the Swedish Museum of Natural History (SMNH).

The holotype (MNHN MO-01) and four paratypes of the new species were fixed in 99\% ethanol (SMNHType-8333; SMNH-Type-8536). One non-type specimen of $A$. tuberculatus (SMNH-123461) was fixed in 99\% ethanol. The fixation method of the holotype of A. maini (NIWA 7564, H-733) is unknown.

Ossicles of one paratype of the new species (SMNH-Type-8536) and of A. tuberculatus (SMNH-123461) were isolated by immersion in domestic bleach (approximately 5\% sodium hypochlorite solution), washed in deionized water, dried in air, and mounted on SEM stubs using double-sided conductive tape. The preparations were sputter-coated with gold-palladium and examined with a HITACHI S-4300 SEM at the Seto Marine Biological Laboratory (Kyoto University). A part of the mouth frame, aboral shields, and oral interradial plates of one paratype of the new species (SMNH-Type-8536) and A. tuberculatus were exposed by dissolving skin with domestic bleach.

The terms used to describe ophiuroids follow Stöhr et al. (2012) and Okanishi et al. (2013). Familial level systematics follow Okanishi \& Fujita (2013).

The number and arrangement of plate-shaped ossicles on the distal side of the adoral shields (Figs $2 \mathrm{H}, 6 \mathrm{~F}, 7 \mathrm{~F}-\mathrm{G}$ ) is an important character for the classification of Asterostegus. They were described as "interradial plates" by Mortensen (1933b: 297) and as "ventral interradial plates" by McKnight (2003: 389). McKnight's "ventral interradial plates" is a relatively unambiguous description because it clearly indicates the position of the plate. However, "ventral" is not usually used for ossicles on the oral frame. Here, we suggest that the ossicles should all be referred to as "oral interradial plates". Bar-shaped ossicles on the aboral and lateral side of arms are also an important taxonomic character (Fig. 7I). These ossicles were described by Mortensen (1933b: 298) as "lateral bars" and by McKnight (2003: 389) as "dorsolateral plate". The "dorsolateral plates" is a term easily confused with the "lateral arm plates" of ophiuroids. We propose the use of "lateral bars" in this study. The lateral bars are present on the proximal portion of the arms of Asterostegus. A pair of bars covers the lateral and aboral side of each arm segment and carry tubercles on their aboral surface.

\section{Results}

Superfamily Euryalidea Gray, 1840

Family Euryalidae Gray, 1840

Genus Asterostegus Mortensen, 1933

Asterostegus Mortensen, 1933a: 4, 40; 1933b: 297.

Asterostegus - Fell 1960: 10. — McKnight 2003: 385-386.

Type species: Asterostegus tuberculatus Mortensen, 1933, by monotypy.

\section{Diagnosis}

Arms simple, not branching. Tubercles present on radial shields and aboral arms. Oral interradial plates present on distal side of adoral shields. Teeth triangular. Oral papillae domed, granule-shaped, present laterally on the jaws. Tentacle pores with two (rarely three) arm spines from fourth arm segment. Oral side of vertebrae with an oral bridge. Lamina of distal arm spines smooth. 
Table 1. A tabular character key to the species of Asterostegus.

\begin{tabular}{|c|c|c|c|c|}
\hline \multirow[b]{2}{*}{ Species } & \multicolumn{3}{|c|}{ Tubercles on aboral surface of the disc } & \multirow{2}{*}{$\begin{array}{l}\text { Numbers and } \\
\text { arrangement of } \\
\text { oral interradial } \\
\text { plates }\end{array}$} \\
\hline & $\begin{array}{l}\text { Number and arrangement } \\
\text { of tubercles on aboral disc }\end{array}$ & $\begin{array}{c}\text { Number of } \\
\text { tubercles on top of } \\
\text { each lateral bar }\end{array}$ & $\begin{array}{l}\text { Length of tubercles } \\
\text { on periphery of } \\
\text { radial shields }\end{array}$ & \\
\hline $\begin{array}{l}\text { A. sabineae } \\
\text { sp. nov. }\end{array}$ & $\begin{array}{l}\text { Two to four, in a line on the } \\
\text { radial shield }\end{array}$ & One or two & ca. $1-1.2 \mathrm{~mm}$ & $\begin{array}{l}\text { One in each } \\
\text { interradius }\end{array}$ \\
\hline $\begin{array}{c}\text { A. maini } \\
\text { McKnight, } 2003\end{array}$ & $\begin{array}{c}\mathrm{Ca} .10, \text { only on periphery } \\
\text { of radial shield }\end{array}$ & Three to five & ca. $250-300 \mu \mathrm{m}$ & $\begin{array}{l}\text { Three to five } \\
\text { arranged in one row }\end{array}$ \\
\hline $\begin{array}{l}\text { A. tuberculatus } \\
\text { Mortensen, } 1933\end{array}$ & $\begin{array}{c}\text { Scattered over entire radial } \\
\text { shield and peripheral part } \\
\text { of aboral disc }\end{array}$ & Two or three & $c a .350 \mu \mathrm{m}$ & $\begin{array}{l}\text { Five to eight } \\
\text { arranged in two } \\
\text { rows }\end{array}$ \\
\hline
\end{tabular}

\section{Remarks}

Based on this study, Asterostegus is currently composed of three species, A. sabineae sp. nov., A. maini McKnight, 2003 and A. tuberculatus Mortensen, 1933. A tabular key to the species of Asterostegus is provided (Table 1).

Species of this genus are distributed in the Indian Ocean, off Madagascar (Mortensen 1933b) and in the Western Pacific, south-east of New Caledonia (McKnight 2003), at a depth of 382-500 m (Fig. 1).

\section{Asterostegus sabineae sp. nov. urn:Isid:zoobank.org:act:D2F3C5E4-B56D-4726-A7B7-FDB56A85B95F}

Figs 2-5

Asterostegus sp. - Okanishi \& Fujita 2013: 568, 575, fig. 1, table 1.

\section{Diagnosis}

Tubercles $c a$. 1-1.2 mm long cover entire radial shields. On proximal portion of arm, one (rarely two) tubercle on each lateral bar. One oral interradial plate present on each interradius.

\section{Etymology}

The specific name is for Dr. Sabine Stöhr of the Swedish Museum of Natural History, eminent Swedish researcher of the Ophiuroidea.

\section{Type material}

MADAGASCAR: Holotype (MNHN IE-2013-8012), three paratypes (SMNH-Type-8333) and one paratype (SMNH-Type-85436), all ethanol preserved specimens, off Madagascar, South Cape, Sainte Marie, $26^{\circ} 16.35^{\prime} \mathrm{S}, 45^{\circ} 10.45^{\prime} \mathrm{E}, 409-473 \mathrm{~m}, 14$ May 2010 , collected during the cruise Atimo Vatae 2010, St. CP3616.

\section{Description}

Measurements. Holotype (MNHN IE-2013-8012): disc diameter $11.7 \mathrm{~mm}$, arm length $118 \mathrm{~mm}$. One paratype (SMNH-Type-8536): disc diameter $13.3 \mathrm{~mm}$, arm length at least $55.4 \mathrm{~mm}$ (arms convoluted). 

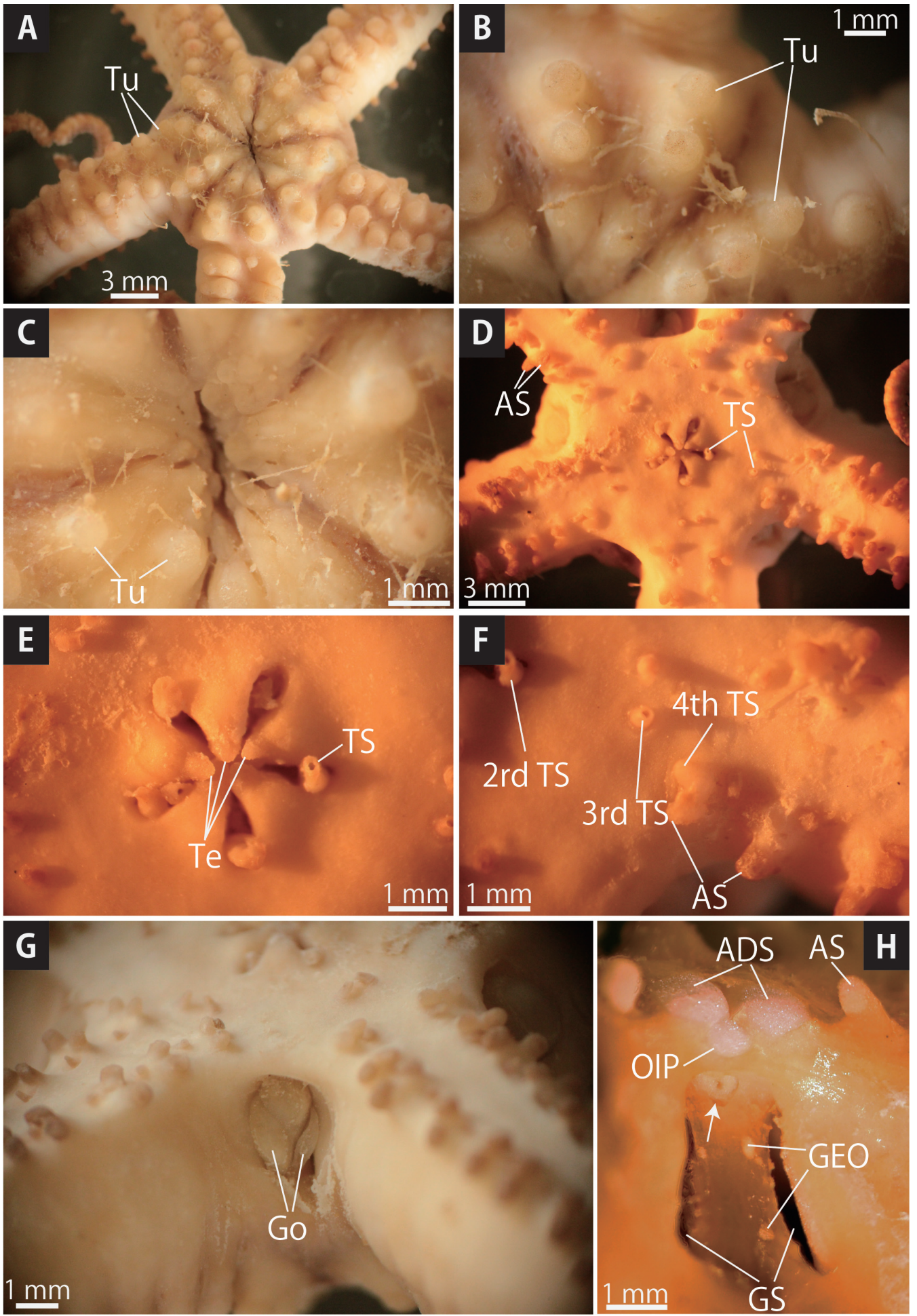

Fig. 2. Asterostegus sabineae sp. nov., holotype (MNHN IE-2013-8012) and one paratype (SMNHType-8536) (H). A. Aboral disc and proximal portion of arms. B. Aboral periphery of disc. C. Aboral central disc. D. Oral disc and proximal portion of arms. E. Jaws. F. Oral periphery of disc and proximal portion of arm. G. Lateral disc. H. Lateral disc, skin removed to observe internal ossicles, an arrow indicates the madreporite; aboral proximal portion of arm. Abbreviations: ADS = adoral shield, AS = Arm spine, $\mathrm{GEO}=$ granule-shaped external ossicles, $\mathrm{Go}=$ gonads, $\mathrm{GS}=$ genital slit, $\mathrm{OIP}=$ oral interradial plate, $\mathrm{Te}=$ teeth, $\mathrm{TS}=$ tentacle sheath, $\mathrm{Tu}=$ tubercle. 
Disc. Disc circular in shape. Radial shields and their surrounds tumid (Fig. 2A). Aboral surface of disc covered by skin and two to four domed tubercles in a line on each radial shield (Fig. 2A-C). Tubercles $c a$. 1.0-1.2 mm long on disc periphery, $c a .0 .8 \mathrm{~mm}$ long at disc center (Fig. 2B). Radial shields, $c a .7 .5 \mathrm{~mm}$
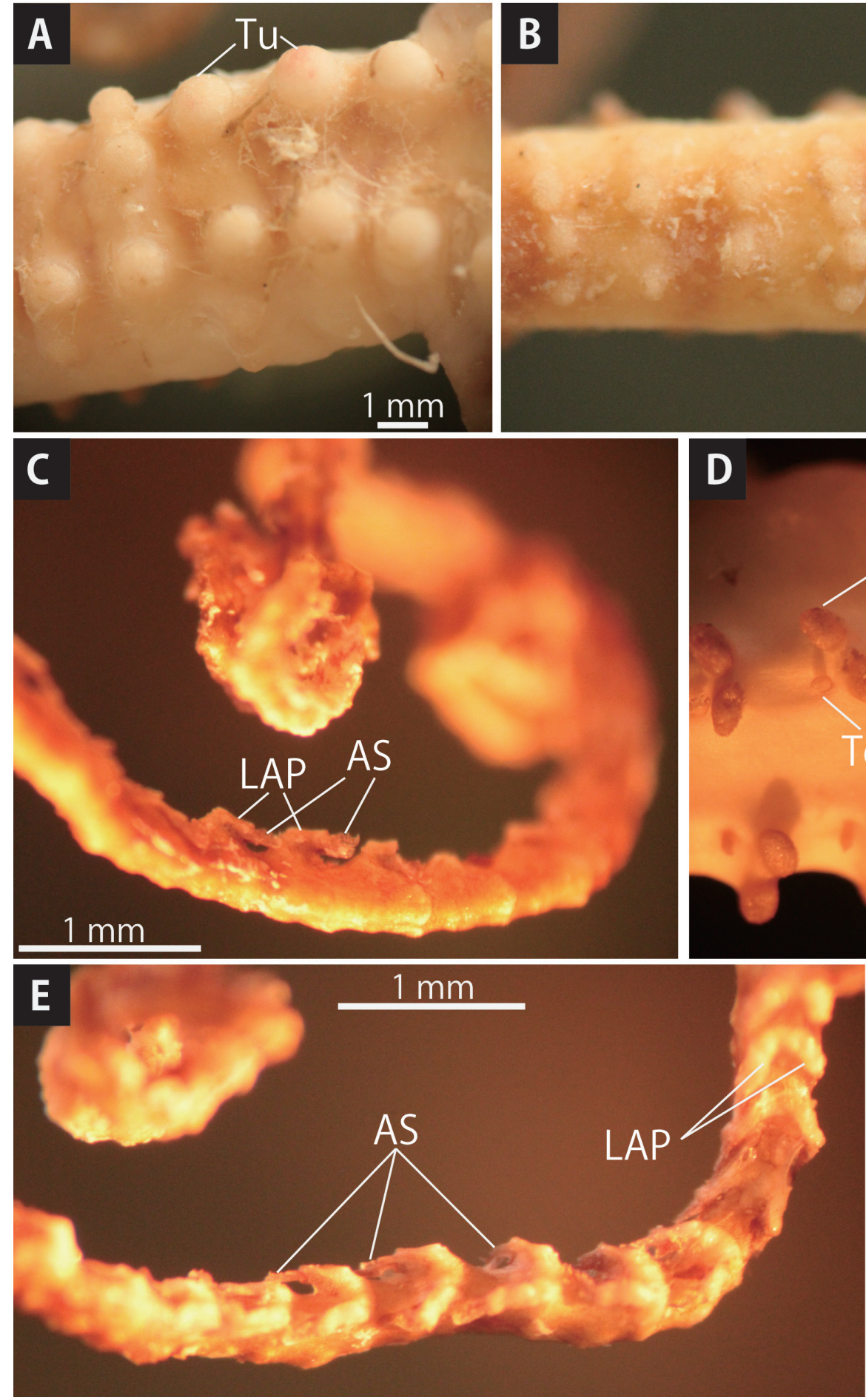

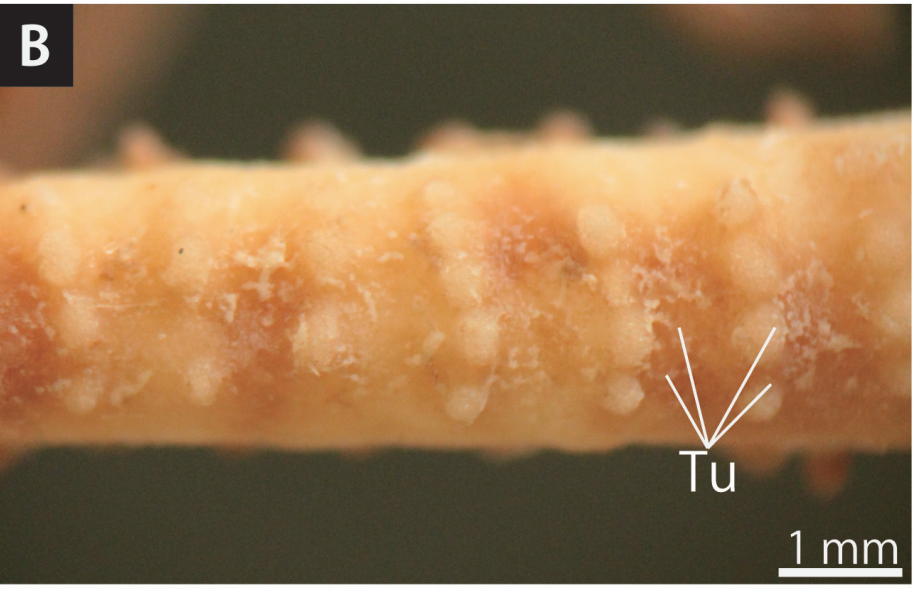

D
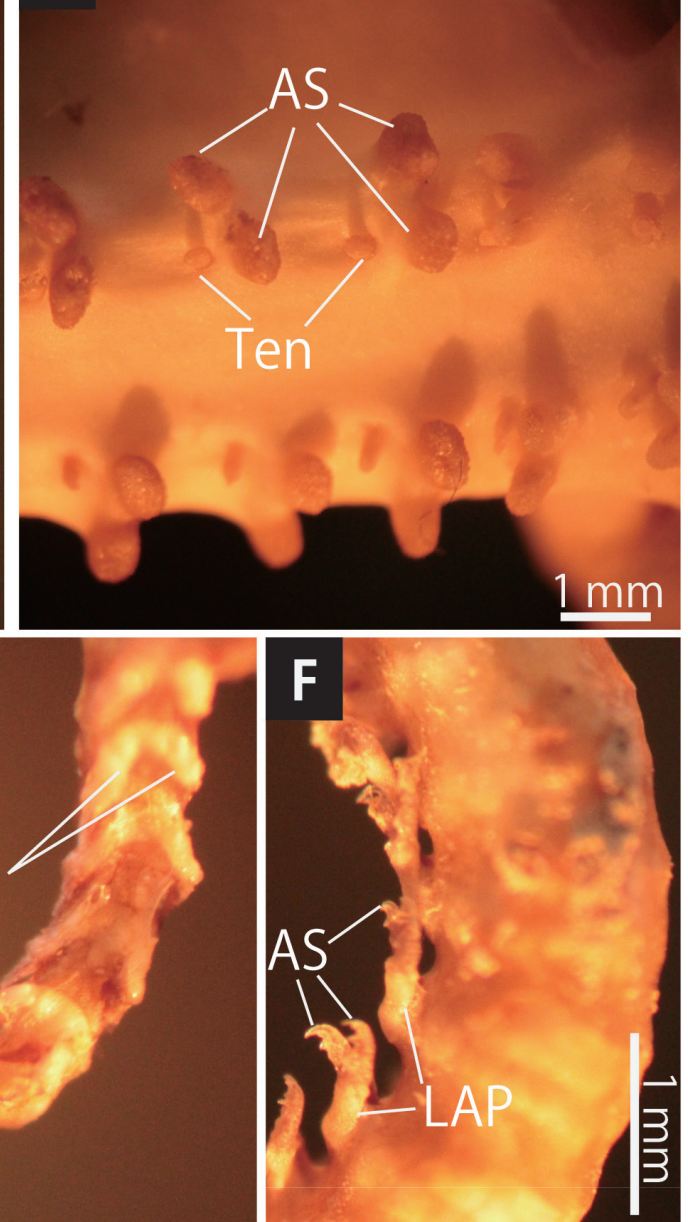

Fig. 3. Asterostegus sabineae sp. nov., holotype (MNHN IE-2013-8012) (A-F). A. Aboral basal portion of arm. B. Aboral middle portion of arm. C. Aboral and lateral distal portion of arm. D. Oral proximal portion of arm. E. Oral middle portion of arm. F. Lateral distal portion of arm. Abbreviations: AS = arm spine, $\mathrm{LAP}=$ lateral arm plate, $\mathrm{Ten}=$ tentacles, $\mathrm{Tu}=$ tubercle. 
long, 0.7-2.7 mm wide, completely covered by skin and tubercles (Fig. 2B-C). Oral surface of disc covered by skin (Fig. 2D-E). More than three triangular teeth form vertical row on dental plate (Fig. 2E). One oral interradial plate present on distal side of adoral shield (Fig. 2H). Lateral interradial surface of disc nearly vertical, covered by skin and granule-shaped external ossicles, $c a$. 150-400 $\mu \mathrm{m}$ long (Fig. 2H). Two genital slits in each interradius, $3.0 \mathrm{~mm}$ long and $0.4 \mathrm{~mm}$ wide (Fig. $2 \mathrm{H}$ ). One madreporite present on distal side of oral interradial plate (Fig. 2H).
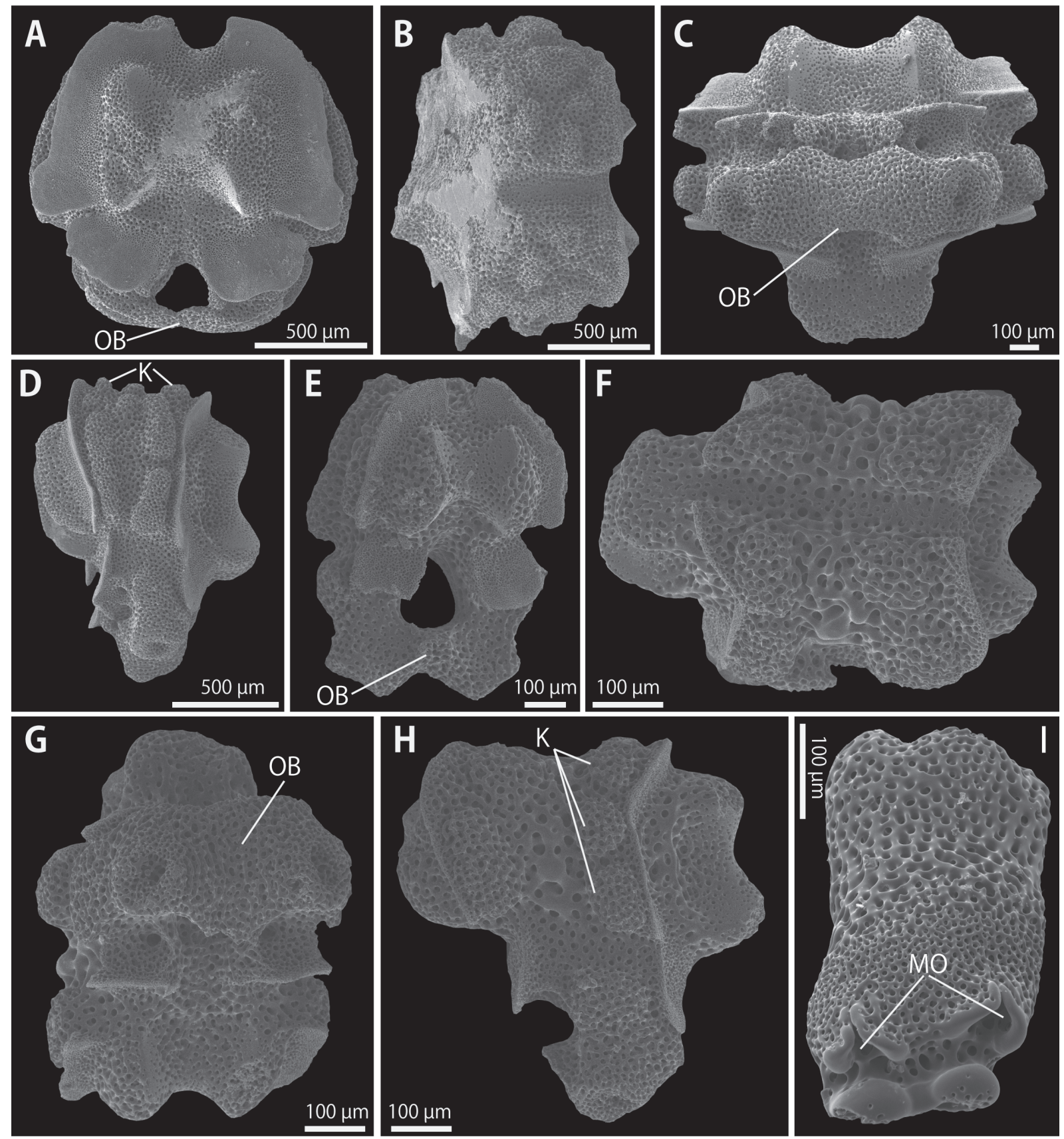

Fig. 4. Asterostegus sabineae sp. nov., paratype (SMNH-Type-8536), SEM photographs. A-D. Vertebrae from middle portion of arm: distal view (A), aboral view (B), oral view (C), lateral view (D). E-H. Vertebrae from distal portion of arm: distal view (E), aboral view (F), oral view $(\mathrm{G})$, lateral view $(\mathrm{H})$. I. Lateral arm plate from middle portion of arm. Abbreviations: $\mathrm{K}=$ knobs, $\mathrm{MO}=$ muscle opening, $\mathrm{OB}=$ oral bridge. 
Arms. Arms simple, five in number, with no abrupt gap in width due to presence of gonads in proximal portion of arms (Figs 2A; 3A). Arms tapering gradually distally. Proximal portion of arms $3.0 \mathrm{~mm}$ wide and $3.7 \mathrm{~mm}$ high, oblong in cross-section. Aboral surface arched and oral surface flattened from middle to distal portion of arms. Proximal portion of the arms covered by skin and one (rarely two) domed tubercles, $c a$. 1.0-1.3 mm long (Fig. 3A), on each lateral bar. If two tubercles present on lateral bar, both are smaller, $c a .800 \mu \mathrm{m}$ long (Fig. 3A). From middle to distal portion of arms, tubercles gradually decrease in size distally, becoming absent near arm tips (Fig. 3B-C). Oral surface of arms covered by skin (Fig. 3D-E). First to third tentacle pores lacking arm spines; two arm spines from fourth pore (Fig. $2 \mathrm{~F}$ ). In proximal third of arms, outer arm spines $c a$. one quarter to half as long as corresponding arm segment, and inner arm spines slightly shorter than outer spines (Figs 2F; 3D). In middle of arms inner and outer arm spines subequal, $c a$. two-thirds as long as corresponding arm segment (Fig. 3D). In distal third of arms, arm spines hook-shaped (Fig. 3F). Inner and outer spines subequal, $c a$. two-thirds as long
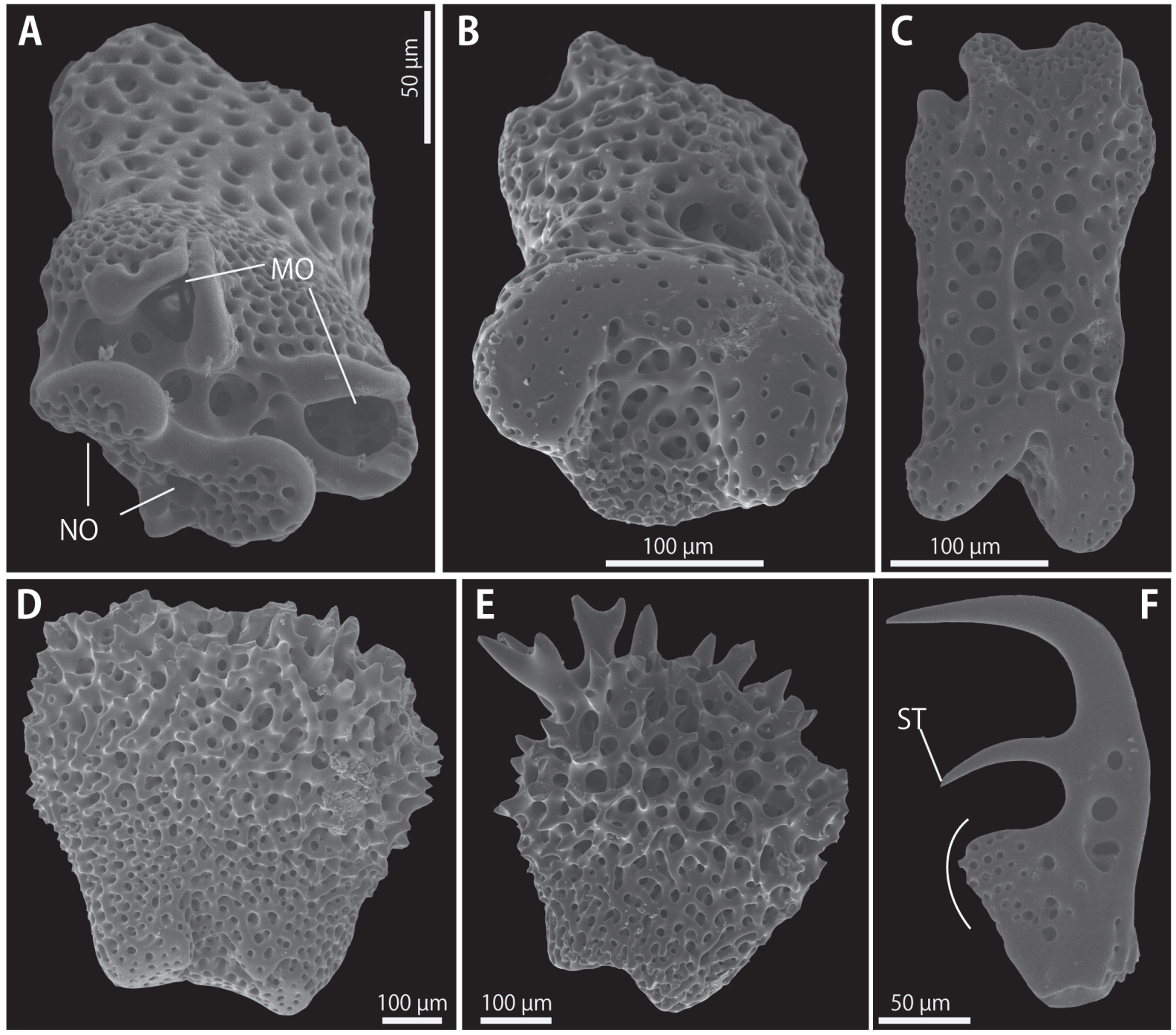

Fig. 5. Asterostegus sabineae sp. nov., paratype (SMNH-Type-8536), SEM photographs. A. Lateral arm plate from middle portion of arm, abradial view. B. Lateral arm plate from distal portion of arm, adradial view. C. Lateral arm plate from distal portion of arm, oral view. D-F. Arm spines: from proximal portion of arm (D), middle portion of arm (E), distal portion of arm, an arc indicates lamina (F). Abbreviations: $\mathrm{MO}=$ muscle opening, $\mathrm{NO}=$ nerve opening, $\mathrm{ST}=$ secondary tooth. 
as corresponding arm segment (Fig. 3C, E-F). Lateral arm plates concealed by skin and visible at distal arm tips where skin becomes thinner (Fig. 3E).

Colour. Body creamy white, arm spines brown (Figs 2A, G, H; 3B, D). Colour in life is unknown.

Ossicle MORPHOLOGY. Ossicles separated from one paratype, SMNH-Type-8536. Vertebrae. Vertebrae with streptospondylous articulations (Fig. 4A, E), oral bridges on oral side (Fig. 4C, G) and knobs on lateral side (Fig. 4D, H), and not inclining from proximal-aboral side to distal-oral side of arms (Fig. 4B, D, F, H) throughout the arms. These features indicate the new species' affiliation to the family Euryalidae. Knobs on proximal portion of arms elongated, becoming rounded toward distal portion of arms (Fig. 4D, H).

LATERAL ARM PLATES. Lateral arm plates in middle portion of arms with two pairs of muscle and nerve openings, each of them associated with arm spine articulation (Figs 4I, 5A-C). Dorsal and ventral lobes beside muscle openings contact each other, a tubercle structure present between each muscle and nerve opening (Figs 4I, 5A). Arm spines club-shaped, both $650 \mu \mathrm{m}$ long and wide on proximal portion of arms (Fig. 5D), $450 \mu \mathrm{m}$ long and $500 \mu \mathrm{m}$ wide on middle portion of arms (Fig. 5E), hook-shaped, ca. $230 \mu \mathrm{m}$ long on distal portion of arms, with one secondary tooth and smooth lamina on proximal portion (Fig. $5 \mathrm{~F})$.

\section{Distribution}

Only known from off Madagascar, 409-473 m depth (type locality, present study).

\section{Remarks}

The new species falls within Asterostegus by virtue of having simple arms, tubercles on radial shields and aboral arms, oral interradial plates, triangular teeth and granule-shaped oral papillae, an oral bridge on oral side of vertebrae, and smooth lamina of distal arm spines (Fell 1960; McKnight 2003).

Asterostegus sabineae sp. nov. can be distinguished from the other two species as follows: two to four tubercles on the radial shields of the present new species form a line on each radial shield (Fig. 2A), whereas the tubercles of $A$. maini number $c a .10$ and are scattered on the periphery of the radial shields only (Fig. 6C). Those of $A$. tuberculatus number 5-15 and are scattered over the entire radial shields as well as on the interradial areas and periphery of the aboral disc (Fig. 7A). The size of tubercles of the new species on the periphery of the radial shield is $c a$. 1.0-1.2 mm long (Fig. 2B). In contrast, those of A. maini and A. tuberculatus in the same position are ca. 250-300 $\mu \mathrm{m}$ (Fig. 6C) and ca. $350 \mu \mathrm{m}$ long (Fig. 7A), respectively.

The new species has one or two tubercles on the top of each lateral bar in the arms proximally (Fig. $2 \mathrm{H}$ ), while A. maini and A. tuberculatus have three to five (Fig. 6H), and two to three tubercles (Fig. 7I), respectively.

The number of oral interradial plates of the new species is one on each interradius (Fig. 3F) while there are three to five plates in A. maini (McKnight 2003) and five to eight in A. tuberculatus (Fig. 7G) (Mortensen 1933b). The oral interradial plates of the latter two species form rows (see also the description of $A$. tuberculatus) (McKnight 2003).

Asterostegus maini McKnight, 2003

Fig. 6

Astroceras elegans McKnight, 1989: 25 (non Astroceras elegans Bell, 1917).

Asterostegus maini McKnight, 2003: 386-389, figs 1, 2 (replacement name). 
Asterostegus maini - Okanshi \& Fujita 2013: 568, 571, 575, fig. 1, tables 2-3.

\section{Diagnosis}

About 10 tubercles present on periphery of radial shields, $c a$. 250-300 $\mu \mathrm{m}$ long. On proximal portion of arm, three to five tubercles on top of each lateral bar. Three to five oral interradial plates forming one row.

\section{Type material}

Holotype (NIWA 7564, H-733), ethanol preserved specimen, vicinity of Pukapuka Atoll, Manihiki Plateau, Cook Islands, New Zealand, 1053.0'S, $165^{\circ} 55.2^{\prime} \mathrm{W}-10^{\circ} 52.4^{\prime} \mathrm{S}, 165^{\circ} 55.4^{\prime} \mathrm{W}, 417-446 \mathrm{~m}$ depth, 21 Apr. 1986.

\section{Description}

MeAsurements. NIWA 7564, H-733: disc diameter $22 \mathrm{~mm}$, arm length at least $205 \mathrm{~mm}$ (arms convoluted).

Disc. Disc circular in shape with notched interradial margins (Fig. 6A-B). On aboral surface, radial shields and their surrounds tumid (Fig. 6A, C). Aboral surface of the disc covered by skin and clubshaped tubercles on periphery of radial shields, $c a$. 250-300 $\mu \mathrm{m}$ (Fig. 6C). Radial shields, $c a .10 .0 \mathrm{~mm}$ long and 1.7-2.1 mm wide, and completely covered by skin (Fig. 6D). Oral surface of the disc covered by skin (Fig. 6E). Seven to eight spear head-shaped teeth forming a vertical row on dental plate (Fig. $6 \mathrm{E})$. Domed and granule-shaped oral papillae lying on each side of jaw, but can not be seen when wet (Fig. 6E). Two or three oral interradial plates form a row on proximal side of adoral shields but cannot be seen clearly when wet (Fig. 6F). The oral interradial plates projecting from lateral side of the disc (Fig. 6G). Lateral interradial surface of the disc nearly vertical, covered entirely by skin (Fig. 6G). Two genital slits in each interradius, $1.6 \mathrm{~mm}$ long and $0.2 \mathrm{~mm}$ wide (Fig. 6G).

ARms. Arms simple, five in number, with no abrupt gap in width due to presence of gonads in proximal portion of arms. Arms tapering gradually distally. Proximal portion of the arms $6.7 \mathrm{~mm}$ wide and 7.1 $\mathrm{mm}$ high, oblong in cross-section. Aboral surface arched and oral surface flattened from middle to distal portion of arms. Proximal portion of the arms covered by skin and three or four (rarely five) club-shaped tubercles, $c a$. 170-340 $\mu \mathrm{m}$ long, on each lateral bar (Fig. 6H). Tubercles gradually decrease in size and number distally, becoming absent near arm tips (Fig. 6I). Entire oral surface of arms covered by skin (Fig. $6 \mathrm{~J}$ ). First to third tentacle pores lacking arm spines; fourth pore with two (rarely one or three) arm spines (Fig. 6J). All arm spines on each tentacle pore subequal throughout arms (Fig. 6J, K). In proximal third of arms, arm spines ovoid and minute (Fig. 6J), ca. one-third to two-thirds as long as corresponding arm segment (Fig. 6J). In middle of arms, arm spines club-shaped, as long as corresponding arm segment. In distal third of arms, arm spines hook-shaped, as long as corresponding arm segment (Fig. 6K). Lateral arm plates concealed by skin.

Colour. McKnight (2003) described the colour of the holotype as "In ethanol, areas between radial shields as well as dorsal surfaces of arms light brown, rest of body creamy-white". However, by our observation, the holotype is uniformly creamy white. The colour might be diluted in long term ethanol preservation. Colour in life is unknown.

\section{Distribution}

Only known from off Cook island, 417-446 m depth, New Zealand (type locality, McKnight 2003). 

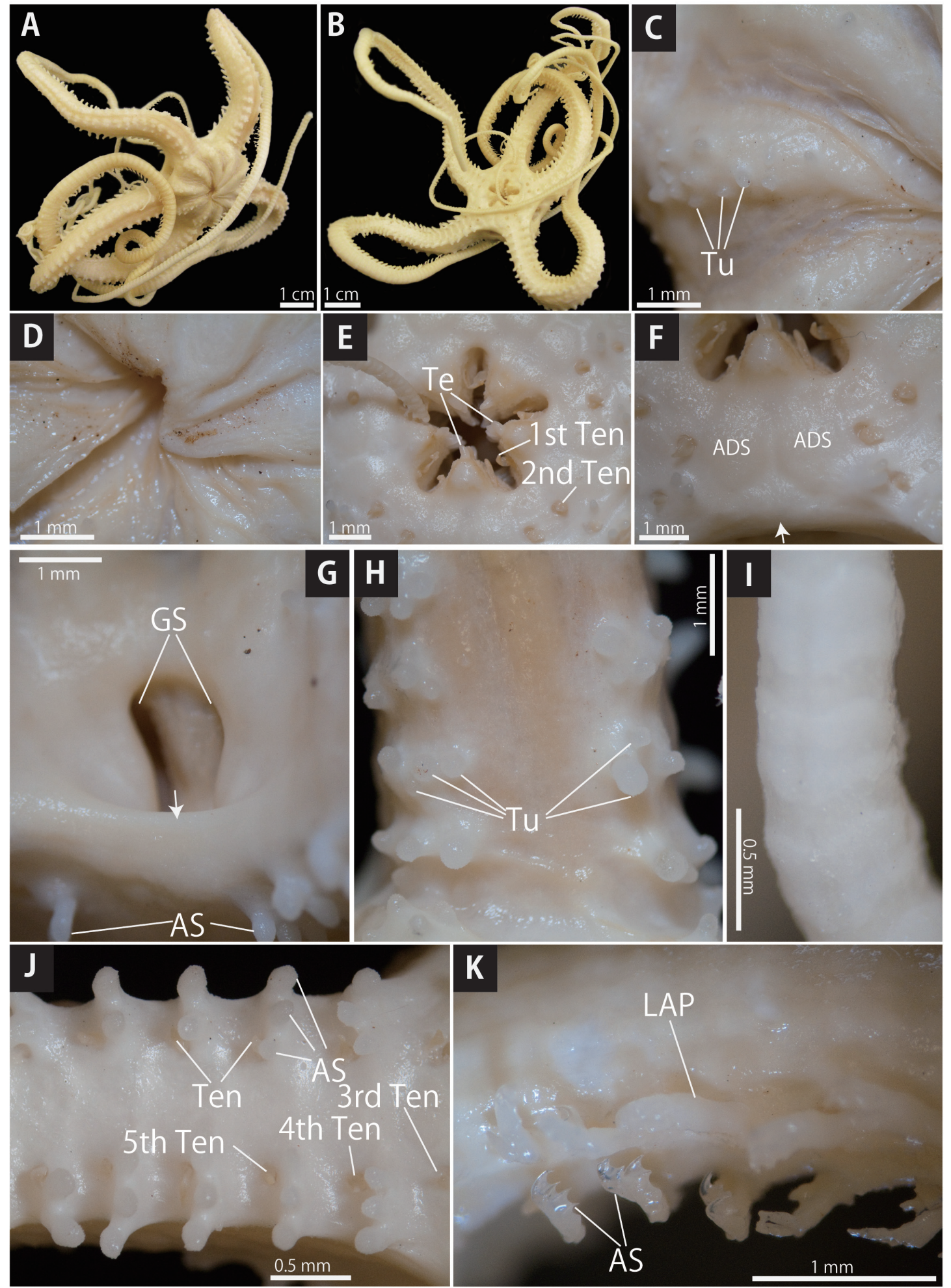

Fig. 6. Asterostegus maini McKnight, 2003 (NIWA 7564, H-733). A. Aboral view. B. Oral view. C. Aboral periphery of disc. D. Aboral central disc. E. Jaws. F. Oral periphery of disc. G. Lateral disc. H. Aboral proximal portion of arm. I. Aboral middle portion of arm. J. Oral proximal portion of arm. K. Lateral middle portion of arm. Arrows indicate positions where oral interradial plates should exist (F, G). Abbreviations: $\mathrm{ADS}=$ adoral shield, $\mathrm{AS}=$ arm spine, $\mathrm{GS}=$ genital slit, $\mathrm{LAP}=$ lateral arm plate, $\mathrm{Te}$ $=$ teeth, $\mathrm{Ten}=$ tentacle, $\mathrm{Tu}=$ tubercle. 


\section{Remarks}

Asterostegus maini is related to A. tuberculatus in sharing relatively small tubercles and multiple oral interradial plates on each interradius, while $A$. sabineae possess relatively large tubercles and only one oral interradial plate.

Asterostegus maini and A. tuberculatus can be distinguished by the size and arrangement of tubercles on the disc, the number of tubercles on lateral bars, and the number and arrangement of oral interradial plates (Table 1, see also remarks for A. sabineae).

Asterostegus tuberculatus Mortensen, 1933

Figs 7-10

Asterostegus tuberculatus Mortensen, 1933: 298-300, figs 24-25, pl. 19; figs 4-5.

Asterostegus tuberculatus - Okanishi \& Fujita 2013: 568, 572, 575, fig. 1, tables 2-3.

\section{Diagnosis}

Tubercles present on periphery of radial shields as well as interradial periphery of disc, $c a .350 \mu \mathrm{m}$ long. On proximal portion of arm, two or three tubercles on top of each lateral bar. Five to eight oral interradial plates forming two rows.

\section{Material examined}

SMNH-123461, one ethanol preserved specimen, west coast of Reunion Island, 500 m, 2009.

\section{Description}

Measurements. SMNH-123461: disc diameter $14.5 \mathrm{~mm}$, arm length $259 \mathrm{~mm}$.

Disc. Disc circular in shape, with notched interradial edges (Fig. 7A). On aboral surface, radial shields and their surrounds tumid (Fig. 7A). Disc surface covered by skin and evenly scattered tubercles (Fig. 7A-C). Tubercles on disc center granule-shaped, $c a .300 \mu \mathrm{m}$ diameter and $400 \mu \mathrm{m}$ height (Fig. 7C) and on periphery club-shaped tubercles, $c a .350 \mu \mathrm{m}$ diameter and $550 \mu \mathrm{m}$ height (Fig. 7B). Radial shields, $c a$. $7.5 \mathrm{~mm}$ long and $0.7-2.0 \mathrm{~mm}$ wide (Fig. 7A), completely covered by skin and tubercles. Oral surface of the disc covered by skin and granule-shaped external ossicles, $c a$. 120-240 $\mu$ m diameter, which are evenly scattered (Fig. 7D, F). Four spearhead-shaped teeth form a vertical row on dental plate (Fig. 7E). Six to seven domed oral papillae lie on each side of jaw (Fig. 7E). Adoral shields somewhat hexagonal-shaped (Fig. 7F). Oral interradial plates pentagonal or hexagonal-shaped, in two rows (Fig. $7 G$ ). Proximal row consists of two oral interradial plates, distal row consists of three interradial plates (Fig. 7G). Lateral interradial surface of disc nearly vertical, covered entirely by skin (Fig. 7H). Two genital slits in each interradius, $4.1 \mathrm{~mm}$ long and $0.7 \mathrm{~mm}$ wide (Fig. $7 \mathrm{H}$ ). One madreporite present between oral side of genital slits (Fig. 7H).

Arms. Arms simple, five in number, with no abrupt gap in width due to presence of gonads in proximal portion of arms. Arms tapering gradually distally. Proximal portion of arms $6.85 \mathrm{~mm}$ wide and $5.5 \mathrm{~mm}$ high, oblong in cross-section. Aboral surface arched and oral surface flattened from middle to distal portion of arms. Proximal portion of arms covered by skin and two or three club-shaped tubercles, ca. $400 \mu \mathrm{m}$ long and $750 \mu \mathrm{m}$ height (Figs 7I; 8J-K), on each lateral bar. On middle portion of arms, tubercles granule-shaped, $c a$. $450 \mu \mathrm{m}$ long (Fig. 9A), one or two on each lateral bar. On oral surface, four to five granule-shaped external ossicles, scattered on each arm segment, $c a$. 150-300 $\mu \mathrm{m}$ long on proximal portion of arms (Fig. 9C) and $c a$. 100-150 $\mu \mathrm{m}$ long on middle portion of the arms (Fig. 9D). Tubercles and external ossicles on oral surface gradually decrease in size distally, becoming absent near 


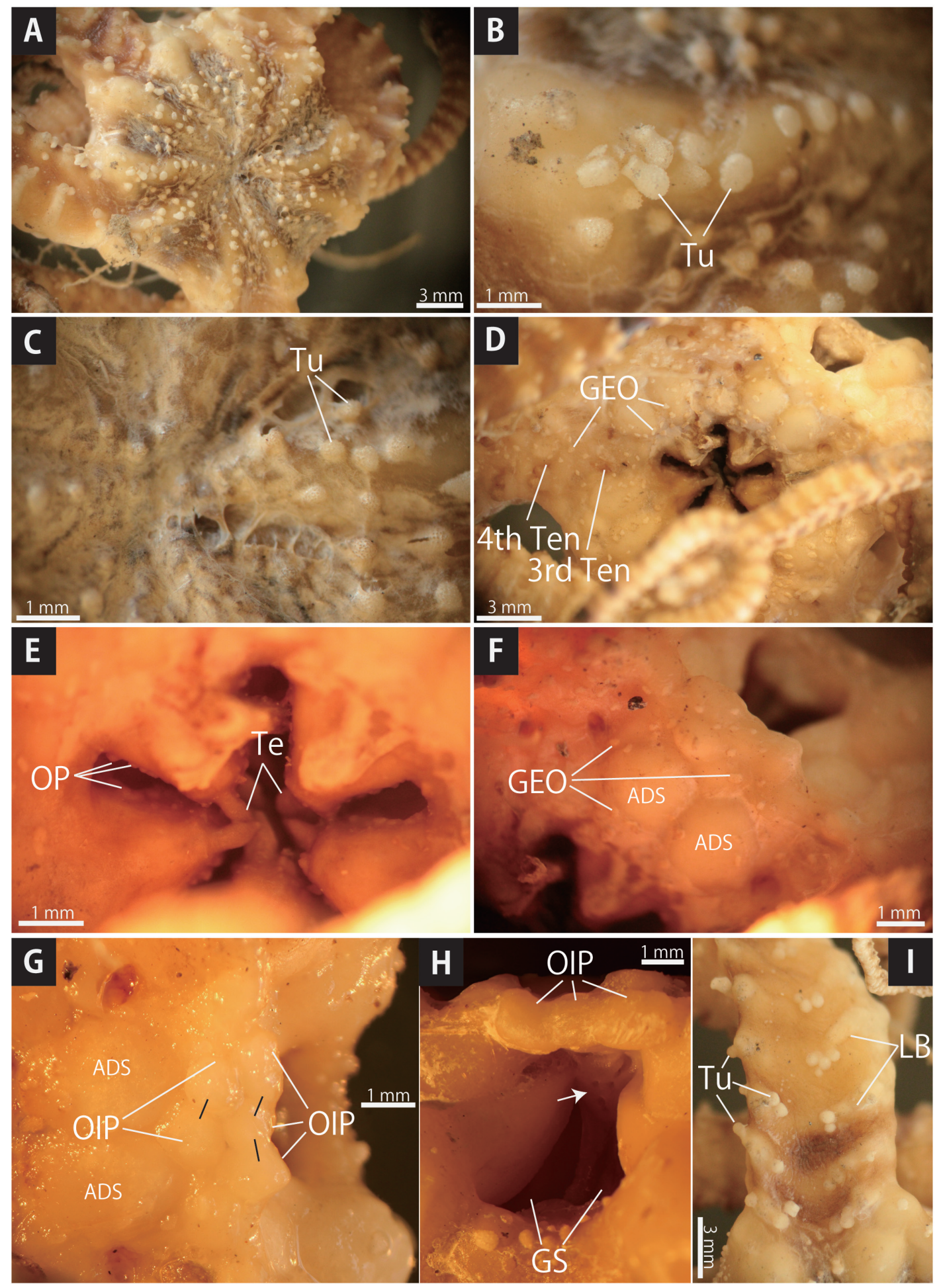

Fig. 7. Asterostegus tuberculatus Mortensen, 1933 (SMNH 123461). A. Aboral disc and proximal portion of arm. B. Aboral periphery of disc. C. Aboral central disc. D. Oral disc. E. Jaws. F. Oral periphery of disc. G. Oral periphery of disc, skin removed to observe internal ossicles, oral interradial plates of the same row are connected by black bars. H. Lateral disc, an arrow indicates madreporite. I. Aboral proximal portion of arm. Abbreviations: ADS $=$ adoral shield, GEO $=$ granule-shaped external ossicle, $\mathrm{GS}=$ genital slit, $\mathrm{LB}=$ lateral bar, $\mathrm{OIP}=$ oral interradial plate, $\mathrm{OP}=$ oral papillae, $\mathrm{Te}=$ teeth, $\mathrm{Ten}=$ tentacle, $\mathrm{Tu}=$ tubercle. 

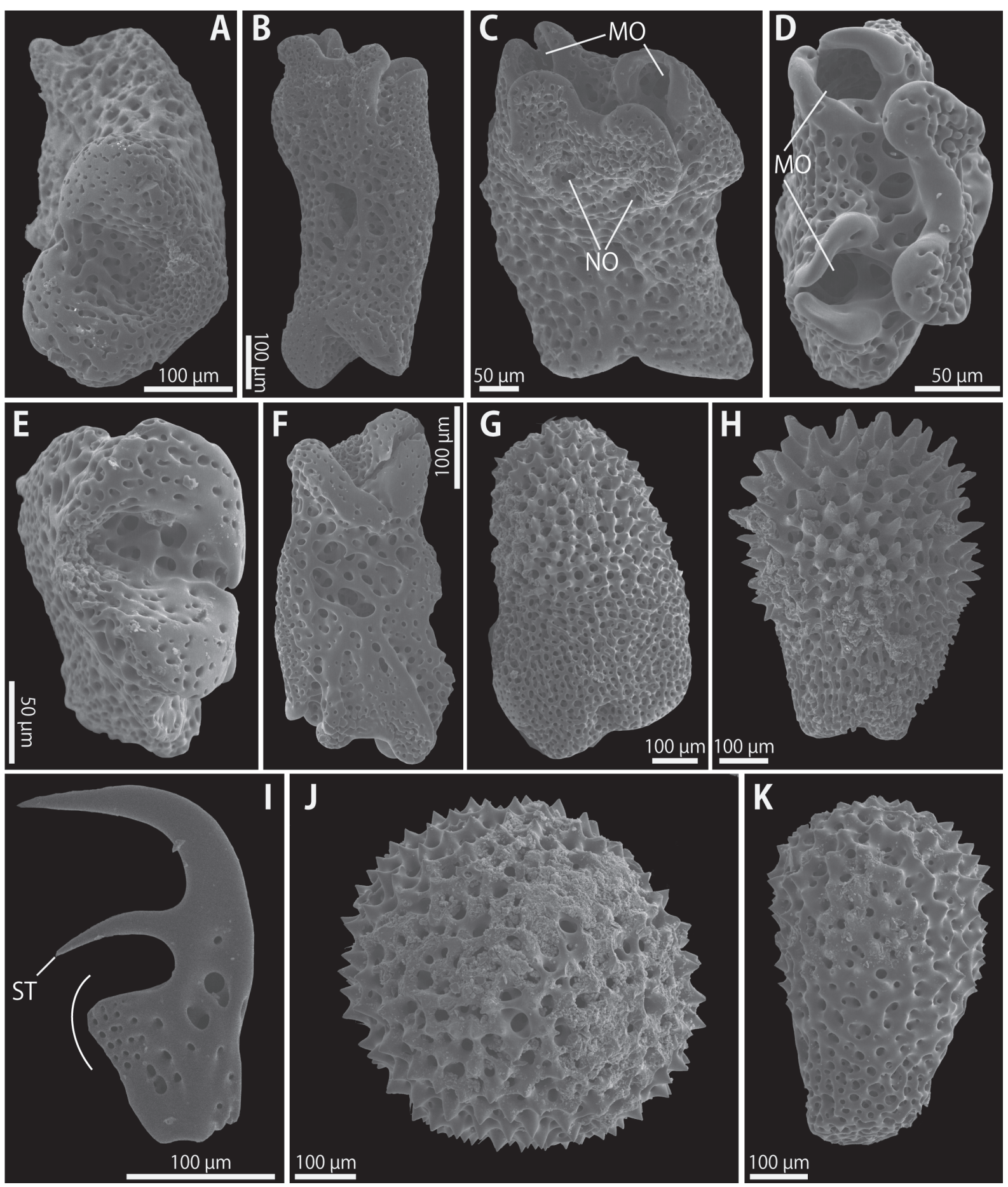

Fig. 8. Asterostegus tuberculatus Mortensen, 1933 (SMNH 123461), SEM photographs. A-C. Lateral arm plates from middle portion of arm: internal view (A), oral view (B) and external view (C). D-F. Late-ral arm plates from distal portion of arm: external view (D), internal view (E) and oral view (F). G-I. Arm spines from proximal portion (G), middle portion $(\mathrm{H})$ and distal portion, an arc indicates lamina (I). J-K. Tubercles on proximal portion of arm: external view $(\mathrm{J})$ and lateral view (K). Abbreviations: $\mathrm{MO}=$ muscle opening, $\mathrm{NO}=$ nerve opening, $\mathrm{ST}=$ secondary tooth . 
arm tips (Fig. 9B, E-F). First to third tentacle pores lacking arm spines; two arm spines from fourth pore (Fig. 7D). In proximal third of arms, arm spines ovoid and minute (Figs 8G; 9C). Outer arm spines $c a$. two-thirds as long as corresponding arm segment, inner arm spines slightly shorter, $c a$. two-thirds as long as outer spine (Fig. 9C). In middle of arm, arm spines club-shaped (Figs 8H; 9D). Inner and outer arm spines of equal length, $c a$. half as long as corresponding arm segment (Fig. 9D). In distal third of arms, arm spines hook-shaped with smooth lamina on distal side (Fig. 9E). Inner and outer spines of equal length, $c a$. one-third as long as corresponding arm segment (Figs 8I; 9E-F). Lateral arm plates concealed by skin and external ossicles, with two pairs of muscle and nerve openings, and each of them associated with an arm spine articulation (Fig. 8A-F). Ventral lobes and dorsal lobes beside muscle openings meet (Fig. 8C-D). A condyle present between each muscle and each nerve opening (Fig. 8C,
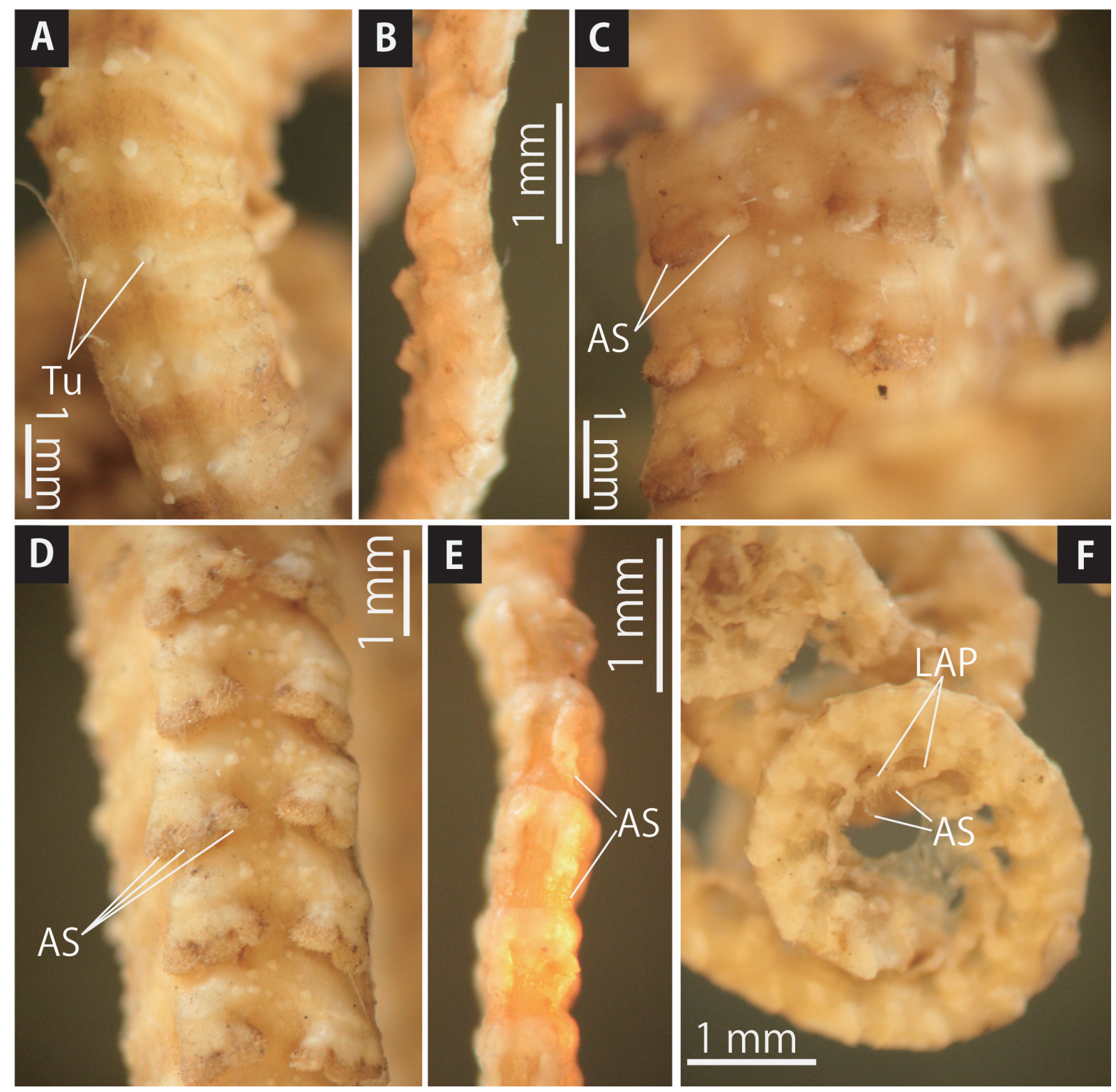

Fig. 9. Asterostegus tuberculatus Mortensen, 1933 (SMNH 123461). A. Aboral middle portion of arm. B. Aboral distal portion of arm. C. Oral proximal portion of arm. D. Oral middle portion of arm. E. Oral distal portion of arm. F. Lateral distal portion of arm. Abbreviations: $A S=$ arm spine, $L A P=$ lateral arm plate, $\mathrm{Tu}=$ tubercle. 

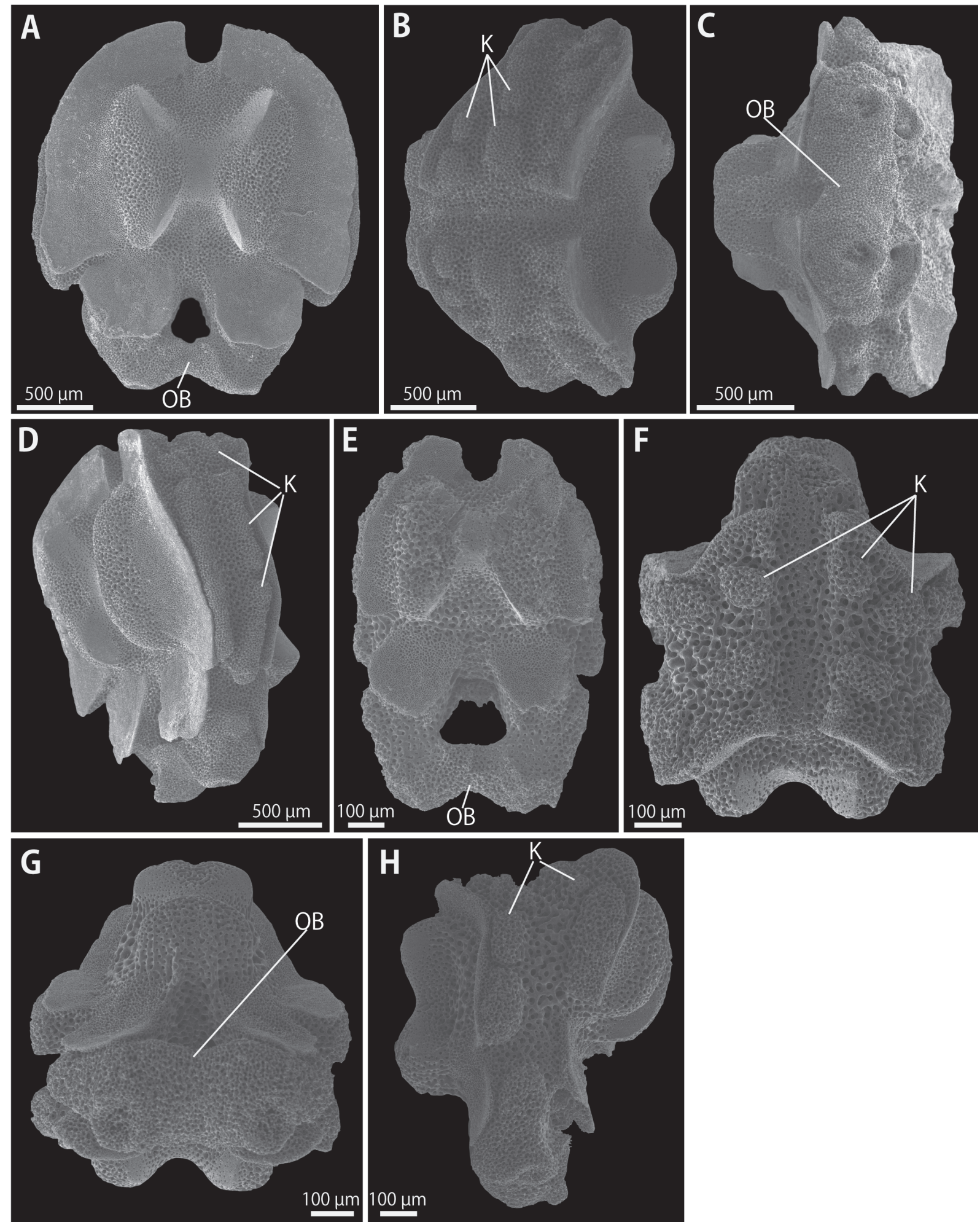

Fig. 10. Asterostegus tuberculatus Mortensen, 1933 (SMNH 123461), SEM photographs. A-D. Vertebra from middle portion of arm: distal view (A), aboral view (B), oral view (C) and lateral view (D). E-H. Vertebrae from distal portion of arm: distal view $(E)$, aboral view $(F)$, oral view $(G)$ and lateral view $(H)$. Abbreviations: $\mathrm{K}=$ knob, $\mathrm{OB}=$ oral bridge. 
D). Vertebrae with streptospondylous articulations (Fig. 10A, E), oral bridges on oral side (Fig. 10A, C, E, G), knobs on lateral side (Fig. 10B, D, F, H). These features indicate A. tuberculatus' affiliation to the family Euryalidae. Knobs on lateral side of vertebrae elongate throughout the arms (Fig. 10B, D, F, H).

CoLour. Uniformly white, slightly grayish on aboral disc surface except radial shields (Fig. 7A). Black spots appear on aboral and lateral arms randomly, every 2-20 arm segments (Fig. 7I). Colour in life is unknown.

\section{Distribution}

Off Durban, 376 m depth, Republic of South Africa (type locality, Mortensen 1933b). Off Reunion Island, $500 \mathrm{~m}$ depth (present study).

\section{Remarks}

Asterostegus tuberculatus can be distinguished from the other two species in the arrangement of tubercles on the disc, numbers of tubercles on lateral bars, and the arrangement of oral interradial plates (Table 1, see also the Remarks for the other two species).

\section{Acknowledgements}

We are most grateful to Sadie Mills (NIWA) for her critical reading of the manuscript and constructive comments. We wish to express our sincere gratitude to Owen Anderson and Kareen Schnabel (NIWA) for their assistance with the examination of the holotype of Asterostegus maini and to Sabine Stöhr (SMNH) for arranging the loans of examined specimens. This work was supported by grants from the Research Institute of Marine Invertebrates (Tokyo), the Showa Seitoku Memorial Foundation, and the Japan Society for the Promotion of Society (Scientific Research [C] No. 22570104, Research fellowships for Young Scientists No. 22506).

\section{References}

Clark A.M. \& Courtman-Stock J. 1976. The Echinoderms of Southern Africa. Trustees of the British Museum (Natural History), London.

Fell H.B. 1960. Synoptic keys to the genera of Ophiuroidea. Zoology Publications from Victoria University of Wellington 26: 1-44.

Kroh A. 2004. First fossil record of the family Euryalidae (Echinodermata: Ophiuroidea) from the middle Miocene of the Central Mediterranean. In: Heinzeller T. \& Nebelsick J.H. (eds) Echinoderms: 447-452. Taylor \& Francis Group, London.

Martynov A. 2010. Reassessment of the classification of the Ophiuroidea (Echinodermata), based on morphological characters. I. General character evaluation and delineation of the families Ophiomyxidae and Ophiacanthidae. Zootaxa 2697: 1-154.

McKnight D.G. 2003. A new species of Asterostegus (Echinodermata: Ophiuroidea) from the Cook Islands, South Pacific Ocean. Species Diversity 8: 385-389.

Mortensen T. 1933a. Studies of Indo-Pacific euryalids. Meddelelser fra Dansk naturhistorisk Forening 96: $1-75$.

Mortensen T. 1933b. Papers from Dr. Th. Mortensen's Pacific Expedition 1914-1916. LXV. Echinoderms of South Africa (Asteroidea and Ophiuroidea). Meddelelser fra Dansk naturhistorisk Forening 93: 215400.

Okanishi M. \& Fujita T. 2009. A new species of Asteroschema (Echinodermata: Ophiuroidea: Asteroschematidae) from southwestern Japan. Species Diversity 14 (2): 115-129. 
Okanishi M. \& Fujita T. 2011a. Two new species of the subgenus Asteroporpa (Astromoana) (Ophiuroidea: Euryalida: Gorgonocephalidae) from Japan. Zootaxa 2751: 25-39.

Okanishi M. \& Fujita T. 2011b. A taxonomic review of the genus Astrocharis Koehler (Echinodermata: Ophiuroidea: Asteroschematidae) with a description of a new species. Zoological Science 28 (2): 148157. http://dx.doi.org/10.2108/zsj.28.148

Okanishi M., Jennifer M.O. \& Fujita T. 2013. A taxonomic review of the genus Asteromorpha Lütken (Echinodermata: Ophiuroidea: Euryalidae). The Raffles Bulletin of Zoology 61 (2): 461-480.

Okanishi M. \& Fujita T. 2013. Molecular phylogeny based on increased number of species and genes revealed more robust family-level systematics of the order Euryalida (Echinodermata: Ophiuroidea). Molecular Phylogenetics and Evolution 69: 566-580. http://dx.doi.org/10.1016/j.ympev.2013.07.021

Okanishi M. \& Fujita T. 2014. A taxonomic review of the genus Astrodia (Echinodermata: Ophiuroidea: Asteronychidae). Journal of the Marine Biological Association of the United Kingdom 94 (1): 187-201. http://dx.doi.org/10.1017/S0025315413001331

Stöhr S., O’Hara T.D. \& Thuy B. 2012. Global diversity of brittle stars (Echinodermata: Ophiuroidea). PLoS ONE 7 (3): e31940. http://dx.doi.org/10.1371/journal.pone.0031940

Manuscript received: 25 November 2013

Manuscript accepted: 6 January 2013

Published on: 6 March 2014

Topic editor: Rudy Jocqué

Desk editor: Kristiaan Hoedemakers

Printed versions of all papers are also deposited in the libraries of the institutes that are members of the EJT consortium: Muséum National d'Histoire Naturelle, Paris, France; National Botanic Garden of Belgium, Meise, Belgium; Royal Museum for Central Africa, Tervuren, Belgium; Natural History Museum, London, United Kingdom; Royal Belgian Institute of Natural Sciences, Brussels, Belgium; Natural History Museum of Denmark, Copenhagen, Denmark. 